\title{
Capsule Shape
}

National Cancer Institute

\section{Source}

National Cancer Institute. Capsule Shape. NCI Thesaurus. Code C48336.

A cylindrical shape that is rounded at both ends. 